\title{
Pneumoscrotum: report of two different cases and review of the literature
}

This article was published in the following Dove Press journal:

Therapeutics and Clinical Risk Management

9 April 2015

Number of times this article has been viewed

\author{
Giovanni Cochetti' \\ Francesco Barillaro' \\ Emanuele Cottini' \\ Francesco D'Amico' \\ Alberto Pansadoro' \\ Solajd Pohja' \\ Andrea Boni' \\ Roberto Cirocchi ${ }^{2}$ \\ Veronica Grassi \\ Rosa Mancuso' \\ Elisa Silvi' \\ Katifenia loannidou' \\ Maria Giulia Egidi' \\ Giulia Poli' \\ Ettore Mearini' \\ 'Department of Surgical and \\ Biomedical Science, Institute of \\ Urological, Andrological Surgery \\ and Minimally Invasive Techniques, \\ University of Perugia, Terni, Italy; \\ ${ }^{2}$ Department of Surgical Sciences, \\ University of Perugia, Terni, Italy
}

Correspondence: Veronica Grassi Department of Surgical Sciences, University of Perugia, Str Tristano di Joannuccio, I, 05100 Terni, Italy Tel +390744205459

Email veronicagrassi@hotmail.it

\begin{abstract}
Pneumoscrotum is the term used to describe the presence of air within the scrotum and includes scrotal emphysema as well as pneumatocele. The etiology varies; in some cases, pneumoscrotum may be due to life-threatening disease like pneumothorax or Fournier gangrene. Despite this, pneumoscrotum is a rarely debated issue. We present two different cases of pneumoscrotum and a review of the literature. The first case report is about a 29 year old male patient affected by Duchenne syndrome who showed pneumoscrotum after cardiopulmonary resuscitation that was performed for asphyxic crisis and cardiovascular arrest. We carried out local puncture with an 18-gauge needle, and the pneumoscrotum was successfully solved. The second case report is about a 56 year old male with pneumoscrotum due to Fournier gangrene who underwent radical exeresis of all necrotic tissues and drainage. This is why most of the scrotal skin and all of the penis skin were removed; as a result, the testicles, epididymis, and cavernosa corpora were externalized. On postoperative day one, the patient was feverless and underwent hyperbaric chamber therapy. No postoperative complications occurred. Accurate evaluation of the pneumoscrotum is always needed. Despite the benign course of most of the clinically evident pneumoscrotum cases, this condition should never be underestimated.

Keywords: cardiopulmonary resuscitation, Fournier gangrene, pneumoscrotum, spontaneous causes, traumatic causes
\end{abstract}

\section{Introduction}

Pneumoscrotum is the term used to describe the presence of air within the scrotum. The incidence of pneumoscrotum is not clear, and probably the real incidence is underestimated because the condition is often not reported. Pneumoscrotum includes scrotal emphysema as well as pneumatocele. Scrotal emphysema is palpable and typically shows clinical signs such as swelling of the scrotum and palpable crepitus. Pneumatocele is not palpable because the air is present within the tunica vaginalis of the testicle. ${ }^{1}$ Intrascrotal gas may not manifest as crepitus or as classic subcutaneous emphysema but more often may appear as diffuse swelling and, eventually, edema. The lack of subcutaneous emphysema in pneumoscrotum may be due to gas tracking along the transversalis fascia, which forms the innermost layer of the covering of the spermatic cord. ${ }^{2}$ The etiologies vary; in some cases pneumoscrotum may be due to a life-threatening disease, such as pneumothorax or Fournier gangrene (FG). Despite this, pneumoscrotum is a rarely debated issue. We present two different cases of pneumoscrotum and a review of the literature.

\section{Case I presentation}

A 29 year old male affected by Duchenne syndrome with mild left systolic dysfunction and chronical respiratory distress arrived on trans-tracheostomic jet-ventilation 
(continuous positive airway pressure [CPAP]: inspiratory pressure [PI] $20 \mathrm{~cm} \mathrm{H}_{2} \mathrm{O}$; positive end-expiratory pressure

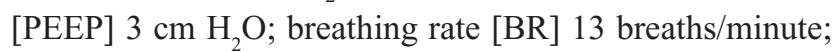
inspiratory time [TI] 1-2 seconds) and was admitted to our emergency room for cyanosis, asphyxic crisis, and cardiovascular arrest due to the obstruction of the tracheostomic tube by necrotic tissue after home care substitution. The patient underwent cardiopulmonary resuscitation with success. After this maneuver, pneumoscrotum occurred. At the time of the clinical examination, massive subcutaneous emphysema had spread through the anterior wall of the abdomen to the scrotum, where pneumoscrotum was evident. An electrocardiogram taken after the resuscitation showed sinusal tachycardia with aspecific abnormalities of the repolarizing phase. The high resolution X-ray computed tomography scan of the chest showed a marked ectasia of the trachea, in correspondence with the endotracheal tube, with thin fluid level in the context; a basal pneumothorax on the left base with major thickness of $28 \mathrm{~mm}$ and a secondary $7 \mathrm{~mm}$ flap of apical pneumothorax on the right side were also highlighted. Apical emphysematous blebs of the left lung and scar tissue were also present. Pneumoperitoneum was evident. A flap allowed air to diffuse through the abdominal wall to the scrotum bilaterally; this resulted in pneumoscrotum (Figure 1). We carried out local puncture with an 18-gauge needle, and the pneumoscrotum was successfully resolved. The patient died 2 days after the resuscitation from acute respiratory distress syndrome due to the progression of the Duchenne syndrome.
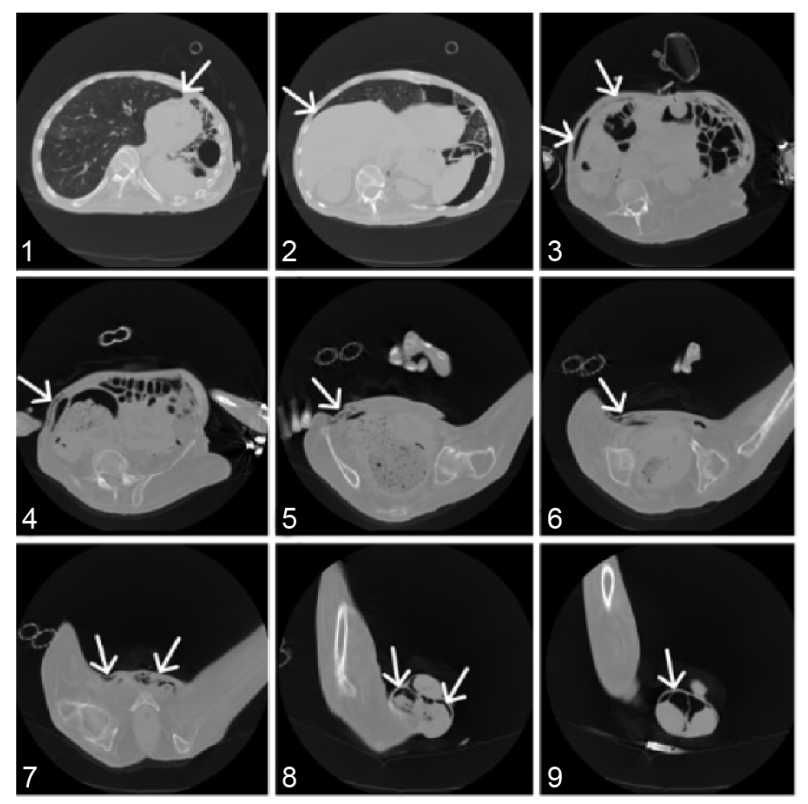

Figure I Computed tomography scans of pneumoscrotum in the patient in case report I. Note: The arrows show the air-path of the pneumoscrotum.

\section{Case 2 presentation}

A 56 year old male patient was referred to the emergency room of our hospital with a fever $\left(39^{\circ} \mathrm{C}\right)$, scrotal swelling, necrotic areas of the scrotum, and penis skin swelling from necrosis. During a clinical exam, it was discovered that an irreducible, bilateral, tension pneumoscrotum associated with edema of the scrotum and the penis had developed. The patient did not report pain. The patient was also affected by severe diabetes mellitus with poor medical control due to the patient's low compliance. Cultural specimens of blood, urine, and dermal surfaces were collected, and the blood was analyzed. The leucocyte count was $14.29 \times 10^{3} / \mathrm{mm}^{3} ; 87 \%$ of the leukocytes were neutrophils and $2.9 \%$ were basophils. The concentration of hemoglobin was $8.9 \mathrm{~g} / \mathrm{dL}$, and the concentration of glucose was $247 \mathrm{mg} / \mathrm{dL}$. Sodium was $134 \mathrm{mEq} / \mathrm{L}$. Serum creatinine was $2.24 \mathrm{mg} / \mathrm{dL}$ with an estimated glomerular filtration rate of $32.36 \mathrm{~mL} / \mathrm{min}$. Inflammation markers were collected, too. The erythrocyte sedimentation rate was $120 \mathrm{~mm} / \mathrm{h}$. The concentration of pseudocolinesterase was 4,187 units/L, and the concentration of procalcitonine was $13.79 \mathrm{ng} / \mathrm{mL}$. The C-reactive protein concentration was $30.23 \mathrm{mg} / \mathrm{dL}$. The cultural specimen of urine was negative. The specimen of the dermal surface was positive for Staphylococcus warneri. The diagnosis of FG was done, and 6 hours later the patient underwent surgical toilet with antibiotic therapy including trimethoprim-sulfamethoxazole, meropenem, tigecycline, and an antimycotic prophylaxis with micafungin (Figure 2). We performed radical debriding of all necrotic tissues and drained the pus. For this purpose, the most of scrotal skin and all of the penis skin were removed; this procedure externalized the testicles, epididymis, and cavernosa corpora (Figure 3). A second procedure within 48 hours was not necessary because of the adequacy of the initial debridement. On the first postoperative day, the fever disappeared, and the patient was transferred to another hospital in order to undergo hyperbaric chamber therapy. No postoperative complications occurred. After 1 month, the patient was in good health without progression of necrotic areas or signs of local or systemic infection. As of this writing, the patient is undergoing reconstructive surgery of the scrotum wall. Written informed consent was obtained from this patient for the publication of this case report and the accompanying images.

\section{Discussion}

The most common causes of pneumoscrotum include traumatic factors, such as thoracic trauma, and iatrogenic factors, such as the colonic perforation after endoscopic polypectomy. 


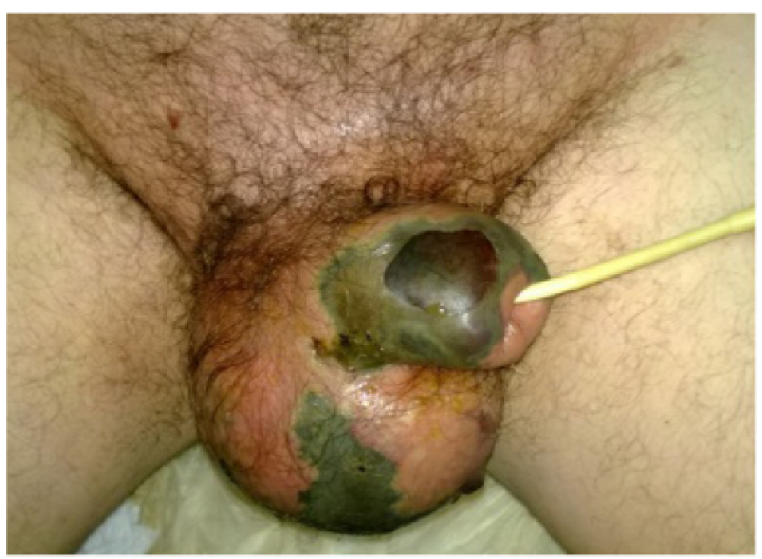

Figure 2 Necrotic tissues of the patient in case report 2.

Pneumoscrotum is also due to spontaneous causes including spontaneous pneumothorax, perforation of hollow abdominal organs, and gas-producing bacterial infections. ${ }^{2}$ Three physiopathological mechanisms may explain pneumoscrotum. One is that the infection could be caused by gas-producing bacteria, which cause the diffusion of air through the subcutaneous tissues (eg, FG) or the direct access of the air to the scrotum. Another mechanism could include the presence of an air layer in the abdominal hollow; this air could spread by diffusion

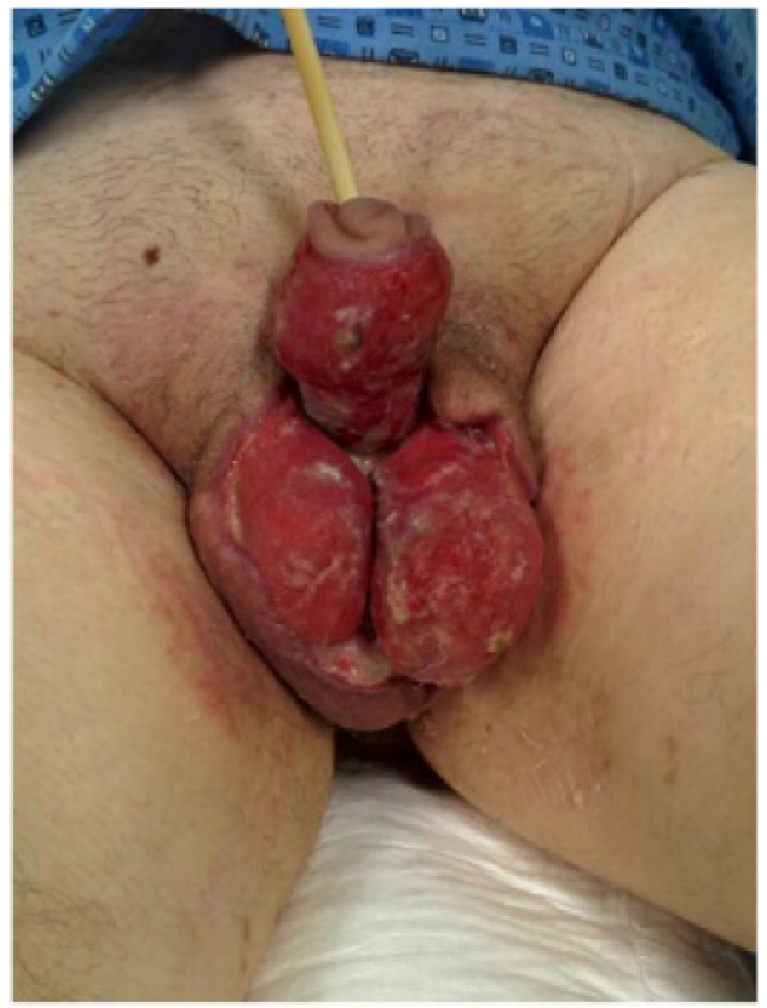

Figure 3 For the patient in the second case report, most of the scrotal skin and all of the penis skin were removed; this externalized the testes, epididymides, and cavernosa corpora. through the fascial planes or across different peritoneal defects into the scrotum. An embryological defect of the processus vaginalis is present in $15 \%-30 \%$ of the male adults and in $60 \%$ of the infants. This anatomy is generally the result of visceral perforations either in a case of spontaneous perforation due to infections or in a case of iatrogenic perforation. Colonic perforation secondary to operative colonoscopy is uncommon, and its reported incidence range is $0.073 \%-2.14 \%{ }^{3,4}$ The third possible mechanism is the air spreading from the lungs due to pneumothorax, pneumomediastinum, or thoracic traumas. In the case of pneumothorax, the air disseminates through Camper's fascia and Scarpa's fascia up to the scrotum via a connective tissue across the abdominal segments. The superficial and deep fascial planes of the Camper's and Scarpa's fascia are distinct in the abdomen but fuse at the corona of the penis, where they form the Colles fascia; even in the testicles, they blend together and generate the Dartos' fascia. Pneumomediastinum, too, may cause air to spread through periesophageal and periaortic fascial planes and then to the diaphragmatic hiatus, where air is allowed direct access into the perinephric space and can cause pneumoretroperitoneum. The air can diffuse through the inguinal canal and along the spermatic fascia to the scrotum. Lastly, the sternocostal margin of the diaphragm may allow the diffusion of an air layer to the abdominal hollow and pelvis through direct communication. The first case of pneumoscrotum was described in 1912 after a nephrostomy. ${ }^{5}$ Until now, few cases have been reported to be caused by pathological, traumatic, or iatrogenic processes. A systematic bibliographic research from January 1972 until December 2013 was conducted in PubMed and Scopus. Two authors (GC, FB) independently performed online bibliographic searches in order to identify titles and abstracts of interest. Full texts of relevant articles were further assessed for inclusion in this study. In this way we included 58 articles. To our knowledge, 59 cases of pneumoscrotum were described (Table 1). Traumatic and iatrogenic causes accounted for $66 \%$ of all pneumoscrotum cases ( 39 cases out of 58 total). Spontaneous causes accounted for $29 \%$ (17 of 58), and the reasons for the remaining 5\% (3 of 58) of the reviewed cases are unknown (Figure 4). By themselves, the endoscopic colonic procedures and the abdominal endoscopy accounted for 32\% (13 of 39) of all the reported cases of pneumoscrotum caused by iatrogenic complications. Laparotomic surgery accounted for $15 \%(6 / 39)$, and blunt chest trauma accounts for $13 \%(5 / 39)$ of all of the traumatic or iatrogenic cases. Chest drainage insertion affected 10\% (4/39) of these cases, while thoracic surgery, laparoscopic surgery, and assisted or jet ventilation each account for 8\% (3/39). Only one case of 
Table I The 59 reported cases of pneumoscrotum from the literature search

\begin{tabular}{|c|c|c|c|c|c|c|}
\hline & Author & Age & Year & Cause & Traumatic & Spontaneous \\
\hline I & Lostoridis et $\mathrm{al}^{6}$ & 82 & 2013 & Blunt chest trauma & $x$ & \\
\hline 2 & Khan and Narasimhan ${ }^{7}$ & 0 & 2012 & Enterocolitis & & $x$ \\
\hline 3 & Boumans et $\mathrm{a}^{8}$ & 65 & 2012 & Cholangiography & $x$ & \\
\hline 4 & Wilson et $\mathrm{al}^{9}$ & 46 & 2012 & Jet ventilation & $x$ & \\
\hline 5 & Netsch et al ${ }^{10}$ & 59 & 2012 & Long term ventilation & $x$ & \\
\hline 6 & Hill et al" & 81 & 2012 & Jejunum perforation & & $x$ \\
\hline 7 & Cakmak et al ${ }^{12}$ & 70 & 2011 & Colonoscopy & $x$ & \\
\hline 8 & Silák et al ${ }^{13}$ & & 2011 & ERCP & $x$ & \\
\hline 9 & Khan and Akhtar ${ }^{14}$ & 0 & 2010 & Abdominal perforation & & $x$ \\
\hline 10 & Patel and Barnacle ${ }^{15}$ & 12 & 2011 & Abdominal perforation & & $x$ \\
\hline II & Su et $\mathrm{al}^{16}$ & 44 & 2011 & Blunt chest trauma & $x$ & \\
\hline 12 & Toro et $\mathrm{al}^{17}$ & 17 & 2010 & Perforated peptic ulcer & & $x$ \\
\hline 13 & Akdogan et $\mathrm{al}^{18}$ & 66 & 2010 & Flexible rectosigmoidoscopy & $x$ & \\
\hline 14 & Heiner et al ${ }^{19}$ & 16 & 2009 & Blunt chest trauma & $x$ & \\
\hline 15 & De'Ath ${ }^{20}$ & $\mathrm{~N} / \mathrm{A}$ & 2008 & Sigmoid diverticulum perforation & $x$ & \\
\hline 16 & Simaioforidis et $\mathrm{a}^{21}$ & 22 & 2008 & Traumatic pneumothorax & $x$ & \\
\hline 17 & Di Capua Sacoto et $a^{22}$ & & 2008 & Bilateral tension pneumotorax & & $x$ \\
\hline 18 & Das and Tappouni ${ }^{23}$ & 55 & 2007 & Duodenal ulcer perforation & & $x$ \\
\hline 19 & Singh and Thakur ${ }^{24}$ & 81 & 2008 & Colonoscopic polypectomy & $x$ & \\
\hline 20 & Yang et $\mathrm{al}^{25}$ & 66 & 2007 & Colonic perforation & & $x$ \\
\hline 21 & Graepler et $\mathrm{al}^{26}$ & 65 & 2007 & Colonoscopic polypectomy & $x$ & \\
\hline 22 & Casey and Al-Dousari ${ }^{27}$ & & 2006 & Multiple chest drain insertion & $x$ & \\
\hline 23 & Fu et $a^{28}$ & 52 & 2005 & Colonoscopy & $x$ & \\
\hline 24 & Martínez-Ordaz et $\mathrm{al}^{29}$ & & 2005 & Colonic surgery & $x$ & \\
\hline 25 & Mazraany et $\mathrm{a}^{30}$ & & 2004 & Laparotomic gastrostomy & $x$ & \\
\hline 26 & Golpe Gómez et $\mathrm{al}^{31}$ & & 2002 & Chest trocar insertion & $x$ & \\
\hline 27 & Kono et $\mathrm{al}^{32}$ & & 2002 & Chest drainage insertion & $x$ & \\
\hline 28 & Koh and Sheu ${ }^{33}$ & 0 & 2002 & Intestinal atresia & & $x$ \\
\hline 29 & Sy et $\mathrm{a}^{34}$ & 2 & 2001 & Necrotizing fasciitis & & $x$ \\
\hline 30 & Aslan et $\mathrm{a}^{35}$ & 0 & 1999 & Gastric perforation & & $x$ \\
\hline 31 & Katkhouda et $\mathrm{a}^{36}$ & $N / A$ & 1999 & Laparoscopic herniorrhaphy & $x$ & \\
\hline 32 & Trübel et al ${ }^{37}$ & 0 & 1998 & Tension pneumothorax & & $x$ \\
\hline 33 & Raudat et $\mathrm{a}^{38}$ & 53 & 1996 & Pulmonary resection & $x$ & \\
\hline 34 & Stavem and Høivik ${ }^{39}$ & & 1996 & Tension pneumothorax & & $x$ \\
\hline 35 & Di Vita et a $\left.\right|^{40}$ & & 1996 & Laparoscopic abdominal procedure & $x$ & \\
\hline 36 & Tan et $\mathrm{al}^{41}$ & & 1995 & Laparoscopic varicocelectomy & $x$ & \\
\hline 37 & Wakabayashi and Bush ${ }^{42}$ & & 1994 & Blunt chest trauma & $x$ & \\
\hline 38 & Heimbach et $\mathrm{al}^{43}$ & & 1993 & Thoracic surgery & $x$ & \\
\hline 39 & Firman et al' & 79 & 1993 & Fournier gangrene & & $x$ \\
\hline 40 & Hasel et $\mathrm{a}^{44}$ & & 1993 & Cholecystectomy & $x$ & \\
\hline 41 & Watson et al ${ }^{45}$ & & 1992 & Two unknown cases & $\mathrm{N} / \mathrm{A}$ & $\mathrm{N} / \mathrm{A}$ \\
\hline 42 & Coppes et $\mathrm{al}^{46}$ & 0 & 1991 & Meckel's diverticulum perforation & & $x$ \\
\hline 43 & Millmond and Goldman ${ }^{47}$ & & 1991 & Chest drainage insertion & $x$ & \\
\hline 44 & Menzies et $\mathrm{al}^{48}$ & & 1991 & Cardiopulmonary resuscitation & $x$ & \\
\hline 45 & Klimach et $\mathrm{al}^{49}$ & & 1990 & Endoscopic sphinterectomy & $x$ & \\
\hline 46 & Garcia and Markowitz ${ }^{50}$ & & 1987 & Gastric perforation & & $x$ \\
\hline 47 & Zikrillaev and Zikrillaev ${ }^{51}$ & & 1985 & Kidney surgery & $x$ & \\
\hline 48 & Redman and Pahls ${ }^{52}$ & & 1985 & Tracheal intubation & $x$ & \\
\hline 49 & Humphreys et $\mathrm{al}^{53}$ & & 1984 & Colonoscopy & $x$ & \\
\hline 50 & Andreani and Buffet ${ }^{54}$ & & 1984 & Colonoscopic polypectomy & $x$ & \\
\hline 51 & Bray $^{55}$ & & 1982 & Pneumoperitoneum & $x$ & \\
\hline 52 & Fishman and Goldman ${ }^{56}$ & & $198 \mid$ & Colonoscopy & $x$ & \\
\hline 53 & Engelhard et al ${ }^{57}$ & 5 & 1981 & Percutaneous liver biopsy & $x$ & \\
\hline 54 & Christenson et $\mathrm{al}^{58}$ & & 1980 & Peritoneoscopy & $x$ & \\
\hline 55 & Archer $^{59}$ & & 1974 & Surgical thoracic emphysema & $x$ & \\
\hline 56 & Williams and Simmons ${ }^{60}$ & & 1974 & Perinephric abscess & & $x$ \\
\hline 57 & Castellanos et $\mathrm{al}^{|6|}$ & & 1973 & Unknown & $N / A$ & $N / A$ \\
\hline 58 & Dencker ${ }^{62}$ & & 1972 & Colonic anastomotic leakage & $x$ & \\
\hline
\end{tabular}

Abbreviations: N/A, not assessed; ERCP, endoscopic retrograde cholangiopancreatography. 


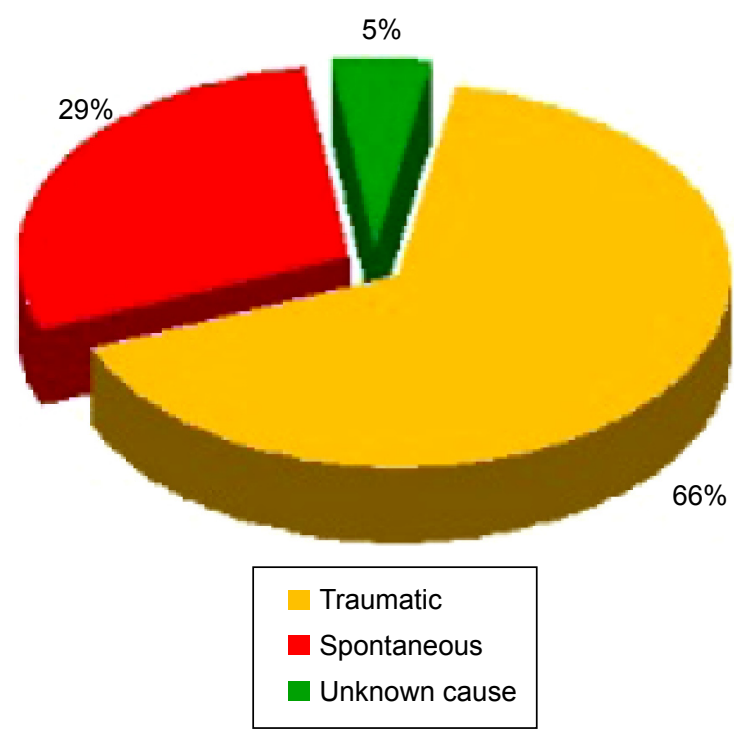

Figure 4 Etiopathogenetic classification and incidence of pneumoscrotum.

pneumoscrotum secondary to percutaneous liver biopsy was reported, which amounted to $3 \%$ in our series (Figure 5). The first case that we described is the second case of pneumoscrotum secondary to cardiopulmonary resuscitation reported in literature. In our case, the pneumothorax caused by the chest compression resulted in air diffusing via a flap through the abdominal wall to the scrotum bilaterally, as shown by the arrows in Figure 1. High quality chest compression has been emphasized to improve the survival of patients with cardiac arrest, and various skeletal injuries were reported. Rib fractures and sternal fractures were the most common skeletal injuries; rib fractures account for $13 \%-97 \%$ of these injuries,

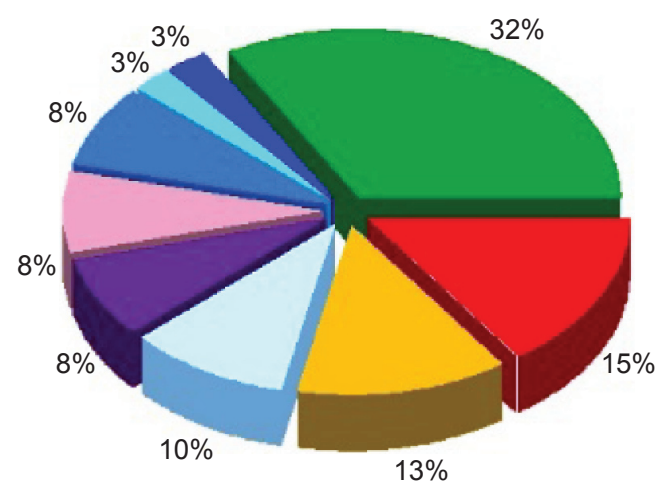

\begin{tabular}{|l|} 
- Abdominal endoscopy \\
Laparotomic surgery \\
Blunt chest trauma \\
Chest drainage insertion \\
Laparoscopic surgery \\
Jet and assisted ventilation \\
Thoracic surgery \\
- Cardiopulmonary resuscitation \\
Percutaneous liver biopsy
\end{tabular}

Figure 5 Causes of traumatic pneumoscrotum. and sternal fractures for $1 \%-43 \%{ }^{6-8}$ Vertebral fractures have been seen less frequently. Pulmonary complications such as hemothorax, pneumothorax, and pneumomediastinum are infrequent but also possible. In this case, a conservative approach was carried out, and the pneumoscrotum was finally resolved. Spontaneous pneumoscrotum is reported less often in literature than is traumatic pneumoscrotum. In our series, 17 cases due to spontaneous causes were described. Of these, $46 \%(8 / 17)$ were due to gastroenteric perforation. Newborns presented a high incidence of pneumoscrotum due to gastric and bowel perforation. The causes were various: congestion of the bowel wall secondary to aspyhxia or septicemia, trauma coincident with delivery, excessive gastric acidity, direct or indirect mechanical injury from gavage tubes or resuscitation maneuver, congenital mural defects of the gastroenteric tract, meconium stasis, rupture of a diverticulum, and coincident central nervous system abnormalities (Figure 6). Although speculation concerning the precise etiology of these perforations is intriguing, it is of far less importance than early recognition of the condition and early and appropriate treatment. Tension pneumothorax accounted for $18 \%$ (3/17) of all cases of reported spontaneous pneumoscrotum. Tension pneumothorax preferably affects young adults; the incidence of pneumothorax is $0.16 \%$ among the entire perinatal population. Therefore, it is worth considering that spontaneous pneumoscrotum is more common among newborns, among whom the incidence of gastrointestinal infection presenting as necrotizing enterocolitis accounted for $12 \%(2 / 17)$ of the spontaneous pneumoscrotum cases in the literature. Necrotizing enterocolitis is the most common gastrointestinal emergency and is the reason for

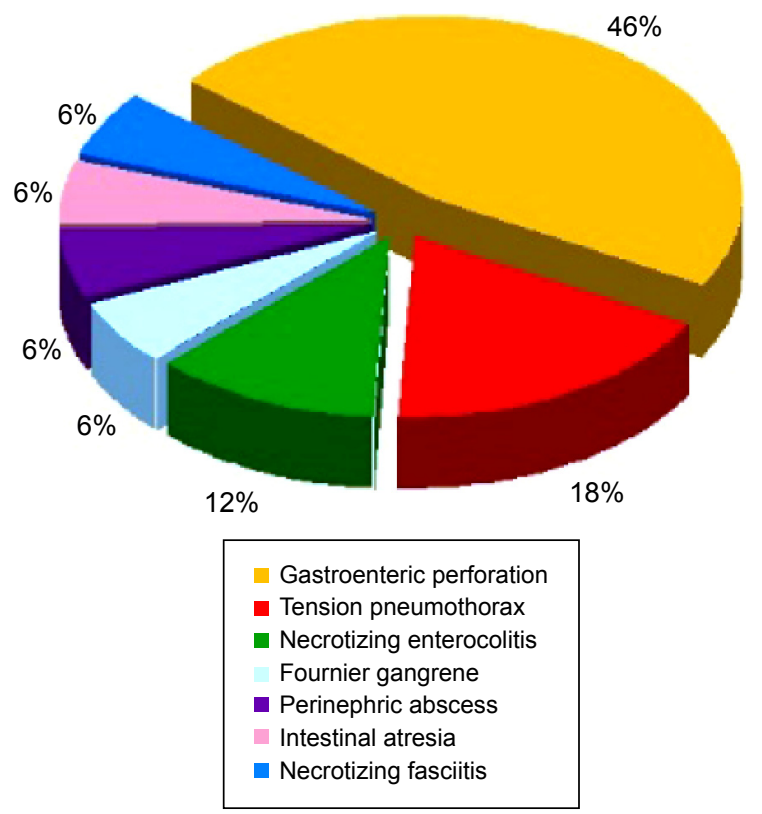

Figure 6 Causes of spontaneous pneumoscrotum. 
$1 \%-8 \%$ of neonatal intensive care unit admissions; the mortality rate for this condition is between $20 \%$ and $40 \%$. ${ }^{9}$ The most consistent risk factors are prematurity, enteral feeding, hypoxia, and bacterial colonization. ${ }^{10}$

Other rare conditions that may occur with pneumoscrotum are the perinephric abscess, the complication of intestinal atresia, and the rare necrotizing fasciitis; each of these represented $6 \%$ of the spontaneous pneumoscrotum cases in our review because there was only one case of each described in our literature search. In our bibliographic research, we found only case reports because no other types of studies on spontaneous pneumoscrotum were available. Furthermore, there are no standardized methods to quantify the grades of the pneumoscrotum cases that are reported. We feel that pneumoscrotum is an underestimated issue; nevertheless, it is often a clinical sign of a life-threatening disease. FG was described in $6 \%(1 / 17)$ of the reported spontaneous pneumoscrotum cases. However, FG is a rare condition; it has an incidence of 1.6 cases per 100,000 males per year $(<0.02 \%$ of hospitals admissions). The mean age of patients with FG is 50.9 years with a major difference in incidence between males and females (male: female ratio for FG is 10:1). ${ }^{11,12}$ The mortality rate varies from $0 \%$ to $88 \%$ and depends on the severity of FG at the time of diagnosis. A diagnosis of FG is clinical, but blood analysis and radiological examinations may be helpful in establishing the severity and in identifying the extent of the necrotic process. In our second case, pneumoscrotum was a sequela of the bacterial infection. The management of FG was consistent with the diagnostic and therapeutic strategies reported in recent literature. ${ }^{11,12}$ Prompt diagnosis and an aggressive surgical debridement with hyperbaric oxygen therapy and broad-spectrum antibiotic combinations guarantee the best outcome.

\section{Conclusion}

In cases of pneumoscrotum, correct evaluation is needed. Some conditions such as torsion, neoplasms, epididymitis and orchitis, hydrocele, spermatocele, hematocele, hernia, and urine extravasation must be considered. Despite the benign course of most of the clinically evident pneumoscrotum cases, this condition should never be underestimated. A careful medical history that considers any thoracic or abdominal trauma or surgery, history of spontaneous pneumothorax, and recent endoscopic procedures is strongly suggested. Surgical puncture can be considered only if a correct diagnosis has been made.

\section{Author contributions}

All authors made substantial contributions to conception and design, acquisition of data, or analysis and interpretation of data; took part in either drafting the article or revising it critically for important intellectual content; gave final approval of the version to be published; agree to be accountable for all aspects of the work in ensuring that questions related to the accuracy or integrity of any part of the work are appropriately investigated and resolved.

\section{Disclosure}

The authors declare that they have no conflicts of interest in this work.

\section{References}

1. Firman R, Heiselman D, Lloyd T, Mardesich P. Pneumoscrotum. Ann Emerg Med. 1993;22(8):1353-1356.

2. Klimach OE, Defriend DJ, Foster DN. Pneumoscrotum following endoscopic sphincterotomy. Surg Endosc. 1990;4(4): 230-231.

3. Ghazi A, Grossman M. Complications of colonoscopy and polypectomy. The Surgical Clinics of North America. 1982;62(5):889-896.

4. Lo AY, Beaton HL. Selective management of colonoscopic perforations. J Am Coll Surg. 1994;179(3):333-337.

5. Keyes EL. Two cases of pneumo-scrotum following nephrectomy. Am J Urol. 1912;8(4):68-71.

6. Lostoridis E, Gkagkalidis K, Varsamis N et al. Pneumoscrotum as complication of blunt thoracic trauma: a case report. Case Rep Surg. 2013;2013:392869.

7. Khan RA, Narasimhan KL. Spontaneous intestinal perforation. Ann Ital Chir. 2012;83(5):437-439.

8. Boumans D, van Zanten RA, Schot BW. A man with painless scrotal swelling. Scrotal emphysema (pneumoscrotum). Neth J Med. 2012;70(4):194-198.

9. Wilson C, Green A, Bader S, Graf D. Pneumoscrotum as the presenting symptom of pneumothorax and pneumoperitoneum after jet ventilation. Anesthesiology. 2012;117(2):408.

10. Netsch C, Bach T, Gross AJ. [Pneumoscrotum as a consequence of long-term ventilation]. Urologe A. 2012;51(2):242-244. German.

11. Hill TW, Mills LD, Butts CJ. Pneumoscrotum after jejunal perforation: a case report. J Emerg Med. 2012;42(3):279-282.

12. Cakmak E, Koyuncu A, Yilmaz A et al. Iatrogenic pneumoscrotum after colonoscopy. Turk J Gastroenterol. 2011;22(4):443-444.

13. Silák J, Nemec L, Ondrák M, Sefr R. [Pneumoscrotum: uncommon sign in duodenal perforation (a case review)]. Rozhl Chir. 2011;90(4): 237-239. Czech [with English abstract].

14. Khan YA, Akhtar J. Pneumoscrotum: a rare presentation of gastric perforation in a neonate. APSP J Case Rep. 2010;1(2):15.

15. Patel C, Barnacle AM. Pneumoscrotum: a complication of pneumatosis intestinalis. Pediatr Radiol. 2011;41(1):129.

16. Su JT, Hsia JY, Hu SY, Tsan YT, Lin TC, Wang LM. Pneumoscrotum after blunt chest trauma. Urology. 2011;77(1):75-76.

17. Toro A, Pulvirenti E, Di Carlo I. Pneumoscrotum due to perforated peptic ulcer previously sutured by laparoscopy. $J$ Laparoendosc $A d v$ Surg Tech A. 2010;20(4):359-361.

18. Akdogan M, Onal IK, Kurt M, et al. Pneumoscrotum associated with nontherapeutic lower gastrointestinal endoscopy. Endoscopy. 2010; 42(Suppl 2):E7-E8.

19. Heiner JD, Skeins EC, Devita D, Litner JS. Scrotal swelling after penetrating chest trauma. West J Emerg Med. 2009;10(4):297.

20. De'Ath HD. Perforation of a sigmoid diverticulum presenting with a pneumoscrotum and surgical emphysema. BMJ Case Rep. 2008;2008:bcr0820080834.

21. Simaioforidis V, Kontos S, Fokitis I, Lefakis G, Koritsiadis S. Subcutaneous emphysema of the scrotum (pneumoscrotum) due to traumatic pneumothorax: a case report. Cases J. 2008;1(1):293. 
22. Di Capua Sacoto C1, Bahilo Mateu P, Ramírez Backhaus M, Gimeno Argente V, Pontones Moreno JL, Jiménez Cruz JF. [Pneumoscrotum secondary to bilateral tension pneumothorax]. Actas Urol Esp. 2008;32(7):756-758. Spanish [with English abstract].

23. Das D, Tappouni R, Houghton R. Renal colic associated with pneumoscrotum. Br J Radiol. 2007;80(960):1025-1027.

24. Singh S, Thakur M. Pneumoscrotum after colonoscopy. Can J Gastroenterol. 2008;22(4):411-413.

25. Yang B, Jiang SX, Fan ZL. [Pneumoscrotum induced by spontaneous colon perforation: a case report and review of the literature]. Zhonghua Nan Ke Xue. 2007;13(8):744-745. Chinese [with English abstract].

26. Graepler F, Lauer UM, Horger MS, Ladurner R, Gregor M. Pneumoscrotum after colonoscopic polypectomy. Endoscopy. 2007;39 (Suppl 1):E90.

27. Casey RG, Al-Dousari S, Murphy D, Power RE. Chest drain insertion may result in the acute scrotum. Scand J Urol Nephrol. 2006;40(1):78-79.

28. Fu KI, Sano Y, Kato S, et al. Pneumoscrotum: a rare manifestation of perforation associated with therapeutic colonoscopy. World J Gastroenterol. 2005;11(32):5061-5063.

29. Martínez-Ordaz JL, Suárez-Romero MA, Monter-Carreola GA, BlancoBenavides R. Pneumoscrotum after colon surgery. Gac Med Mex. 2005;141(2):155-156. Spanish [with English abstract].

30. Mazraany W, Kohli H, Gabriel A, Machado GR, Bojalian MO, Reeves ME. Massive pneumoscrotum following open gastrostomy. Contemp Surg. 2004;60:219-221.

31. Golpe Gómez R, Mateos Colino A, Docasar Bertolo L, Miguélez Vara C. [Spontaneous pneumomediastinum associated with anxiety state]. An Med Interna. 2002;19(7):378-379. Spanish.

32. Kono M, Mizuno T, Kobayashi T, et al. [Scrotal emphysema: a case report]. Hinyokika Kiyo. 2002;48(1):37-39. Japanese [with English abstract]

33. Koh CC, Sheu JC. Intestinal atresia presenting as bilateral scrotal pneumatocele: A case report. J Pediatr Surg. 2002;37(1):E2.

34. Sy ED, Liu CS, Huang SM, Shan YS. Cecal perforation presenting as abdominal-wall necrotizing fasciitis. Pediatr Surg Int. 2001;17(2-3): 215-217.

35. Aslan Y, Sarihan H, Dinç H, Gedik Y, Aksoy A, Dereci S. Gastric perforation presenting as bilateral scrotal pneumatoceles. Turk J Pediatr. 1999;41(2):267-271.

36. Katkhouda N, Campos GM, Mavor E, Trussler A, Khalil M, Stoppa R. Laparoscopic extraperitoneal inguinal hernia repair. A safe approach based on the understanding of rectus sheath anatomy. Surg Endosc. 1999; 13(12):1243-1246.

37. Trübel H, Huth R, Krämer W. Sudden pneumoscrotum in a ventilated infant. Sudden pneumoscrotum as clinical sign of a tension pneumothorax in an infant with tracheal stenosis. Eur J Pediatr. 1998; 157(8):689-690.

38. Raudat CW, Katris F, Woodhall D. Pneumoscrotum: an unusual complication of pulmonary resection. J Am Osteopath Assoc. 1996; 96(6):362-363.

39. Stavem K, Høivik B. [Pneumoscrotum after air leak from tension pneumothorax]. Tidsskr Nor Laegeforen. 1996;116(10):1214-1215. Norwegian [with English abstract].

40. Di Vita G, Frazzetta M, Cortese E, Damiano A. Complications of the laparoscopic access. G Chir. 1996;17(1-2):31-36. Italian [with English abstract]

Therapeutics and Clinical Risk Management

\section{Publish your work in this journal}

Therapeutics and Clinical Risk Management is an international, peerreviewed journal of clinical therapeutics and risk management, focusing on concise rapid reporting of clinical studies in all therapeutic areas, outcomes, safety, and programs for the effective, safe, and sustained use of medicines. This journal is indexed on PubMed Central, CAS,
41. Tan SM, Ng FC, Ravintharan T, Lim PH, Chng HC. Laparoscopic varicocelectomy: technique and results. Br J Urol. 1995;75(4): 523-528.

42. Wakabayashi Y, Bush WH Jr. Pneumoscrotum after blunt chest trauma. J Emerg Med. 1994;12(5):603-605.

43. Heimbach D, Hofmockel G, Wirth M, Frohmüller H. Pneumoscrotum. Case report and review of the literature. Urologe A. 1993;32(6):503-506. German [with English abstract].

44. Hasel R, Arora SK, Hickey DR. Intraoperative complications of laparoscopic cholecystectomy. Can J Anaesth. 1993;40(5 Pt 1): 459-464.

45. Watson HS, Klugo RC, Coffield KS. Pneumoscrotum: report of two cases and review of mechanisms of its development. Urology. 1992; 40(6):517-521.

46. Coppes MJ, Roukema JA, Bax NM. Scrotal pneumatocele: a rare phenomenon. J Pediatr Surg. 1991;26(12):1428-1429.

47. Millmond SH, Goldman SM. Pneumoscrotum after spontaneous pneumothorax with air leak. J Urol. 1991;145(6):1271-1272.

48. Menzies D, Noble JG, Dent CM, Cox PJ. Pneumoscrotum - an unusual complication of cardiopulmonary resuscitation. $\mathrm{Br} \mathrm{J} \mathrm{Urol}$. 1991;67(4):440-441.

49. Klimach OE, Defriend DJ, Foster DN. Pneumoscrotum following endoscopic sphincterotomy. Surg Endosc. 1990;4(4):230-231.

50. Garcia C, Markowitz RI. Pneumoperitoneum and pneumoscrotum caused by gastric perforation. Am J Perinatol. 1987;4(1):75-77.

51. Zikrillaev Z, Zikrillaev MZ. Acute pneumoscrotum after kidney surgery. Urol Nefrol (Mosk). 1985;(4):64. Russian.

52. Redman JF, Pahls WL. Pneumoscrotum following tracheal intubation. J Urol. 1985;133(6):1056-1057.

53. Humphreys F, Hewetson KA, Dellipiani AW. Massive subcutaneous emphysema following colonoscopy. Endoscopy. 1984;16(4): $160-161$.

54. Andreani T, Buffet C. [Subcutaneous abdominal emphysema and pneumoscrotum after endoscopic resection of rectal polyps]. Gastroenterol Clin Biol. 1984;8(4):387. French.

55. Bray JF. Pneumoscrotum with testicular delineation-a new sign of pneumoperitoneum. Br J Radiol. 1982;55(659):867-868.

56. Fishman EK, Goldman SM. Pneumoscrotum after colonoscopy. Urology. 1981;18(2):171-172.

57. Engelhard D, Ornoy A, Deckelbaum RJ. Pneumoscrotum complicating percutaneous liver biopsy. Gastroenterology.1981;80(2):390-392.

58. Christenson PJ, O’Connell KJ, Albert P, Knuff TE. Pneumoscrotum after diagnostic peritonoscopy. Urology. 1980;16(1):78-79.

59. Archer GJ. Pneumoscrotum complicating pneumothorax and surgical emphysema. Br J Urol. 1974;46(3):343.

60. Williams RD, Simmons RL. Citrobacter perinephric abscess presenting as pneumoscrotum in transplant recipient. Urology. 1974;3(4): 478-480.

61. Castellanos R, Rege PR, Evans AT. Pneumoscrotum: a case report and review of the literature. J Urol. 1973;110(2):225-226.

62. Dencker H. Pneumoscrotum as an early sign of anastomic leakage after anterior resection of the colon. Surg Gynecol Obstet. 1972; 134(6):1005

\section{Dovepress}

EMBase, Scopus and the Elsevier Bibliographic databases. The manuscript management system is completely online and includes a very quick and fair peer-review system, which is all easy to use. Visit http://www.dovepress.com/testimonials.php to read real quotes from published authors. 